\title{
Sex-Differentiated Changes in C-Reactive Protein from Ages 9 to 21: The Contributions of BMI and Physical/Sexual Maturation
}

\author{
Lilly Shanahan ${ }^{1,}$, , William E. Copeland ${ }^{2}$, Carol M. Worthman ${ }^{3}$, Alaattin Erkanli ${ }^{2}$, Adrian $^{2}$ \\ Angold $^{2}$, and E. Jane Costello ${ }^{2}$ \\ ${ }^{1}$ University of North Carolina at Chapel Hill \\ ${ }^{2}$ Developmental Epidemiology Program, Duke University Medical Center \\ ${ }^{3}$ Emory University, Department of Anthropology
}

\begin{abstract}
Background-Sex differences in levels of C-reactive Protein (CRP) are well established in adulthood, but little is known about when and why they emerge. Here, we tested longitudinal models of CRP levels from ages 9-21, when marked physical and behavioral changes could contribute to growing sex disparities in CRP.
\end{abstract}

\begin{abstract}
Methods-Data from the community-based prospective-longitudinal Great Smoky Mountains Study $(N=1,420)$ were used. Participants were 9-13 years old at intake and were followed through age 21 . High-sensitivity C-reactive protein (CRP) was assayed from up to nine bloodspot collections per person. BMI, physical/sexual maturation, substance use, and control variables were assessed during yearly interviews to age 16, and at ages 19 and 21 .
\end{abstract}

Results-Multilevel models revealed that the development of CRP in females was best described by a quadratic trend: After slow increases in CRP until age 15, the rate of increase accelerated thereafter. Changes in CRP in males were best described by a smaller, linear increase. After sexdifferentiated associations with BMI, physical/sexual maturation, and substance use variables had been accounted for, increases in CRP after age 15 no longer differed by sex.

Conclusion-Physical/sexual maturation and behavioral changes during adolescence could initiate life-long sex disparities in CRP.

\section{Keywords}

C-reactive protein; sex differences; BMI; adolescence; young adulthood; puberty; testosterone

\footnotetext{
(C) 2013 Elsevier Ltd. All rights reserved.

*Address for Correspondence: Lilly Shanahan, University of North Carolina at Chapel Hill, Department of Psychology, CB \#3270, Davie Hall, Chapel Hill, NC, 27599-3270, lilly_shanahan@unc.edu, phone: (919) 843-6985, fax: (919) 962-2537.

Conflict of Interest Statement

None of the authors have biomedical financial interests or potential conflicts of interest.

Contributors

Each author made substantive intellectual contributions to this article. Dr. Shanahan conceptualized and drafted this manuscript and conducted data analyses. Dr. Copeland helped conceptualize the manuscript, interpret the data, and critically revise the manuscript. Dr. Worthman was responsible for assaying the bloodspots for CRP and testosterone, and she helped with interpreting the data and critical revisions of the manuscript. Dr. Erkanli helped with devising the analytic strategy and data analysis. Drs. Angold and Costello collected the data, helped with interpretation of the data and with critical revisions of the manuscript.

Publisher's Disclaimer: This is a PDF file of an unedited manuscript that has been accepted for publication. As a service to our customers we are providing this early version of the manuscript. The manuscript will undergo copyediting, typesetting, and review of the resulting proof before it is published in its final citable form. Please note that during the production process errors may be discovered which could affect the content, and all legal disclaimers that apply to the journal pertain.
} 
In the absence of acute infection, the acute phase reactant C-reactive protein (CRP) is a marker of low-grade systemic inflammation that is associated with chronic illness and mortality in adulthood (Ridker, 2007; Shah et al., 2009). Currently, CRP > $3 \mathrm{mg} / \mathrm{L}$ is considered a uniform marker of disease risk in both women and men. However, imposing sex-differentiated criteria for CRP remains an ongoing topic of debate, because womenwho typically have a longer life expectancy than men-nevertheless tend to be overrepresented in the CRP $>3 \mathrm{mg} / \mathrm{L}$ group (Khera et al., 2005). This debate is currently missing a critical piece of information: When and why do sex differences in CRP emerge? Here, we examine the developmental origins of sex differences in CRP from ages 9 to 21 -when marked physical and behavioral changes of adolescence could contribute to diverging trajectories of CRP in females versus males.

\section{Trajectories of CRP: Do Sex Differences Emerge During Late Adolescence?}

Longitudinal research describing trajectories of CRP is notably missing, but cross-sectional work suggests that mean levels of high-sensitivity (hs)-CRP undergo no (McDade et al., 2005) or only small (Cook et al., 2000; Ford et al., 2003) age-related increases from middle childhood to mid-adolescence (approximately ages 5-15), temporary accelerations in the rate of increase into young adulthood (Ford et al., 2003), and mostly linear increases throughout adulthood (O'Connor et al., 2009).

Cross-sectional studies also suggest that, compared to men, women typically have higher mean CRP and likelihood of CRP > 3 mg/L [(Ford, 1999; Ford et al., 2004; Khera et al., 2005; Lakoski et al., 2006); for an exception, see Rifai and Ridker, (2003)]. Sex differences in CRP concentrations before young adulthood have not been consistently examined or reported, although one nationally representative study suggests that female-male differences emerge only after age 15, when the aforementioned accelerated temporary increases in CRP are primarily driven by females (Ford et al., 2003).

\section{Correlates of CRP}

Several factors could contribute to sex-differentiated trajectories of CRP during adolescence. Adiposity/obesity/Body Mass Index (BMI)is strongly associated with CRP in both sexes (Dowd et al., 2010; Skinner et al., 2010), but more strongly in women than in men (Visser et al., 1999; Williams et al., 2004; Khera et al., 2009). Sex-differentiated BMI-CRP associations have not been examined or reported earlier in life, but, considering pubertyrelated shifts in body composition, adolescence could mark the beginnings of such sexdifferentiated associations. After puberty, percent body fat is typically greater in women than in men (Gallagher et al., 1996), and the known inflammatory action of fat deposits could contribute to greater CRP in women (Wozniak et al., 2009).

Physical/sexual maturation also results in increased exposure to sex hormones, with potentially different consequences for females and males. External administration of sex hormones (e.g., estrogen) has at least some proinflammatory effects and can increase in females with the use of oral contraceptives (Williams et al., 2004). Endogenous exposure to sex hormones also increases with the onset of puberty and with pregnancies, but its effects on inflammatory markers and overall disease risk in females are less well understood (Eskes and Haanen, 2007). In turn, testosterone increases approximately tenfold more in males than in females during adolescence (Granger et al., 2004), and has anti-inflammatory effects. Thus, unlike later in life when decreases in testosterone contribute to increases in males' disease risk, adolescent increases in testosterone could protect males from elevated CRP (Laaksonen et al., 2003). Apart from sex hormones, behavioral changes of adolescenceincluding the onset of sexual activity and involvement with multiple sexual partners for some adolescents—could also lead to new vulnerabilities to inflammatory processes, 
perhaps especially in females with the onset of vaginal intercourse (Hooton et al., 2000; Dielubanza and Schaeffer, 2011).

Other correlates could contribute to changing levels of CRP over time, but sex differences in associations between these correlates and CRP have not consistently been reported. Substance use, especially nicotine use tends to be positively associated with CRP (O'Connor et al., 2009), and increases during adolescence. The impact of alcohol and illegal drugs on inflammatory processes is less well understood, with some research suggesting that alcohol use is negatively associated with CRP (O'Connor et al., 2009). Ethnicity, including indigenous/Native ethnic background, is robustly correlated with elevated CRP in Canadian and Australian samples (e.g., Retnakaran et al., 2006; Wang and Hoy, 2006), but has not been examined in samples of U.S. children.

\section{Methods and Materials}

\section{Participants}

The Great Smoky Mountains Study (GSMS) is a longitudinal study of the development of psychiatric disorder in rural and urban youth (for detailed descriptions of the study, see Costello et al., 1996; Costello et al., 2003; Copeland et al., 2011). A representative sample of three cohorts of children, age 9, 11, and 13 at intake, was recruited from 11 counties in western North Carolina using a multi-stage selection process. All children scoring above $25 \%$ on a screening questionnaire, plus a 1-in-10 random sample of the rest, were recruited for detailed interviews. About $8 \%$ of the area residents and the sample were African American, and less than 1\% Hispanic. American Indian children were recruited irrespective of their screening score. Through this oversampling procedure, American Indians constituted 25\% of the sample. Of 456 American Indian children identified from school records, $81 \%(n=350)$ participated in the study. Of all subjects recruited, $80 \%(N=1,420)$ agreed to participate. Subjects were assessed annually to age 16, and again at ages 19 and 21. Across all waves, participation rates averaged $84 \%$ (range: $74-94 \%$ ). As explained in the electronic Supplement, all subjects were assigned a sampling weight for statistical analyses; thus, results presented here are representative of the population from which the sample was drawn.

\section{Procedures}

The parent (typically the mother) and subject were interviewed separately until the subject was 16 using the Child and Adolescent Psychiatric Assessment [CAPA; Angold and Costello, (2000)]. Subjects only were interviewed thereafter, using the Young Adult Psychiatric Assessment [YAPA; Angold et al., (1999b)]. Before interviews began, parent and child signed informed consent forms approved by the Duke University Medical Center Institutional Review Board. Each parent and child received an honorarium for their participation. Using a procedure described in detail elsewhere (Worthman and Stallings, 1997), blood samples were obtained at the beginning of each in-person assessment [see also Copeland et al., 2012].

\section{Assessment}

Our high-sensitivity assay for $C$-reactive protein in whole-blood spots was a biotinStreptavidin based immunofluorometric system improving on a previously published method (McDade et al., 2004). Streptavidin A-coated microtiter plates bind a biotinylated capture antibody to CRP, clone $\mathrm{C} 2$. A second Europium-labeled antibody then binds to the Streptavidin A Biotin-C2-CRP complex; fluorescence of the resultant complex is directly proportional to the CRP concentration in each well. Additional information regarding CRP collection and assays, and the calculation of serum equivalents have been reported elsewhere 
(McDade et al., 1997; Worthman and Stallings, 1997; McDade et al., 2004; Copeland et al., 2012). The CRP variable was positively skewed; therefore, it was log10-transformed (after adding 1 to avoid negative numbers upon transformation).

$B M I$ was calculated from weight and height at each assessment.

Physical/Sexual Maturation-Age at menarche was reported by females at each interview up to age 16 (see also Costello et al., 2007). Consistent with previous work in this area, including ours (Copeland et al., 2010), a dichotomous variable indicated whether menarche had occurred before age 11. A dichotomous use of oral contraceptives was assessed in the CAPA/YAPA. Number of pregnancies was assessed in the CAPA/YAPA and coded whether participants had reported 0,1 , or $2+$ pregnancies. Note that the latter three variables were coded 0 ( $=$ no early menarche, no use of oral contraceptives, and zero pregnancies, respectively) for males in analyses involving the entire sample. Ever sexually active was assessed in the CAPA/YAPA and was coded when the subject reported ever having had sexual intercourse. Multiple sexual partners was also assessed in the CAPA/ YAPA and was defined as having two or more sexual partners in adolescence or 10 or more by young adulthood (see also, Copeland et al., 2010). Testosterone (T) was assayed from ages 9 to 16. The blood spot $\mathrm{T}$ assays were a modification of commercially available serum plasma radioimmunoassay kits (Binax, South Portland, ME). Complete details of protocol, validation, performance, sample stability, and comparability to plasma or serum values for each blood spot assay are provided elsewhere (Worthman and Stallings, 1997; Angold et al., 1999a). We did not implement correction for time of day, which could result in increased error variation and, thus, underestimates of T-CRP associations.

Substance use, including current nicotine, alcohol, and illicit drug use was assessed in the CAPA/YAPA. Dichotomous variables coded recent use for each of these substances.

Control variables-A physical health problems survey adapted from the Centers for Disease Control National Health Interview Survey Child Health Supplement (1988) was administered to assess 39 common ailments (e.g., diabetes, anemia, mononucleosis). A dichotomous variable indicated any illness in the past 12 months. Medication use in the past 12 months was assessed from the Child and Adolescent Services Assessment (Ascher et al., 1996), including use of psychotropic or other prescribed medications. Low socioeconomic status (SES) was assessed in the CAPA/YAPA, and was coded if the subject's parents (during childhood) or the subject (during adulthood) reported any two of the following: income below the federal poverty line, low educational attainment (i.e., less than high school graduation), and low occupational status based on the NORC occupational prestige scale.

\section{Missing data}

By age 21, 8,806 assessments were completed. Of these, bloodspots were obtained for 6,087 (69.1\%). Bloodspots were not available either because the subject refused or because the interviews were completed by phone. For in-person interviews, $79.4 \%$ of subjects provided bloodspots. 6,000 samples (98.6\%) were successfully assayed for CRP, but 109 with CRP > $10 \mathrm{mg} / \mathrm{L}$ (indicating current infection) were removed. Altogether, 1,334 of the 1,420 study participants (93.9\%) provided CRP and interview data at some point(s) of the study. The median number of CRP samples per person was 5 .

\section{Analytic Approach}

The analytic strategy was designed to examine trajectories of CRP in females and males, including normative mean trajectories, variation in trajectories, and sources of within- and between-persons variation in CRP. Multilevel modeling (MLM) using PROC MIXED in 
SAS was performed to conduct growth curve analyses on repeated measures of CRP, specifying the covariance matrix as unstructured, using the empirical option to derive robust variance (sandwich type) estimates of fixed effects. Level 1 here represents within-person change and Level 2 represents stable between-persons differences. Accordingly, at Level 1, age, age ${ }^{2}$, and time-varying covariates (e.g., alcohol use) were included to model withinperson change over time. At Level 2, time-invariant, covariates (e.g., ethnicity, sex, early menarche) were used to model between-persons stable differences in trajectories of CRP. Note that we tested interactions with age for all variables, but only report significant interactions below.

A series of increasingly complex models were run in three steps. Briefly, in Step 1, we tested unconditional means models, and then used fit indices to select the best-fitting growth model. In Step 2, individual covariates were included in the prediction of CRP-first bivariately, then taking into account trajectories of CRP, then simultaneously—retaining covariates with $p<.10$. Step 3 repeated all analyses, but to age 16 only, adding testosterone (which was assessed to age 16 only) as a covariate. To reduce complexity, analyses initially were run for females and males separately. In Step 4, sex differences were tested using the entire sample. Supplement 1 provides citations and additional detail for the analytic strategy, including the disaggregation of BMI and testosterone into within- and between-persons contributions.

\section{Results}

Descriptive statistics for all study variables for females and males are shown in Table 1. Although space limitations preclude the reporting of all ethnic differences on covariates, we should note that the most important correlate of CRP, BMI, was higher in American Indians compared to other ethnic groups in the sample: $M=26.98, S D=3.03$ for American Indian; $M=22.15, S D=6.27$ for White; and $M=21.33, S D=5.92$ for African American participants.

\section{Unconditional Means and Basic Growth Curve Models}

Step 1 established unconditional means models and growth curves of CRP from ages 9 to 21. Intra-class correlations (ICC) calculated from these models (Models 1, shaded columns in Table 2) were .34 for females, .36 for males (and .35 for the entire sample). Thus, $35 \%$ of the total variation in CRP was due to between-persons variation (i.e., stable inter-individual differences), whereas $65 \%$ was due to within-person variation (i.e., within-person changes/ fluctuations over time).

Fixed Effects-Next, growth curve models established basic trajectories of CRP (Models 2, white columns in Table 2). Growth in CRP in females was best characterized by a quadratic polynomial function of age. Figure 1 shows little change in CRP from ages 9 to 15, followed by accelerated increases to age 19. In contrast, increases in CRP in males were best characterized by a smaller, linear age term. Sex-differentiated rates of increase were confirmed by an age ${ }^{2}$ by sex interaction for the entire sample $(b=-0.003, S E=0.0006, p<$. 001). Moreover, in a separate model using the entire sample, sex-differentiated increases in CRP after age 15 were captured by an "age 15" by sex interaction $(b=-0.057, S E=0.02, p$ $<.01$; "age 15 " was coded " 0 " for age $\triangle 5$ and " 1 " for age >16). Results also indicated a main effect of ethnicity in both sexes: American Indian participants had higher CRP than did White participants. African American participants did not differ in CRP from White participants. Fit indices did not support age by ethnicity (by sex) interactions. 
Random Effects-Models fit best when the intercept and slope of CRP were allowed to vary randomly across individuals, allowing an individual trajectory for each person. After taking ethnicity (and sex) into account, significant variation in CRP trajectories remained unexplained (i.e., the random coefficients were still significant).

\section{Including Covariates of CRP}

Step 2 (Table 3) added covariates in the prediction of CRP to age 21. For females, results for bivariate models (Model 3) showed that both within- and between-persons effects of BMI were significant: deviating from one's own predicted BMI trajectory and having higher typical/stable BMI levels than other females was associated with higher CRP. When Model 2 was taken into account, both of these BMI variables also interacted with age (for betweenpersons BMI only marginally at $p=.054)$ : within- and between-persons BMI were more strongly associated with females' CRP with increasing age. Thus, low versus high BMI females, and BMI-increasing versus BMI-decreasing females had a widening gap in CRP as age increased. Variables indexing all other correlates were also individually associated with CRP. However, when the basic trajectory of CRP (Model 2) was controlled for, ever sexually active, multiple sexual partners, illicit drug use, low SES, and illness lost significance at $p<.05$ (therefore, these coefficients are not bolded in Table 3 ).

Final growth models for females (Model 4) entered all individual covariates simultaneously, retaining covariates with $p<.10$. Within- and between-persons BMI (and their interactions with age) remained associated with CRP. From the physical/sexual maturation domain, only use of oral contraceptives remained a significant, positive correlate; the pregnancies coefficient was at $p<.10$. Early menarche became non-significant with the inclusion of BMI. Nicotine and medication use remained positively associated with CRP; alcohol use was negatively associated. In these models, the coefficient for American Indians was still significant, but, compared to Model 2 (see Table 2), it had diminished by $70 \%$ to $b=.03, S E$ $=.01, p=.04$. This reduction of the size of the American Indian coefficient was due primarily to the inclusion of the within- and between-persons BMI terms. The age 15 term shrank $42 \%$ from $b=.12$ to $b=.07, S E=.01, p<.001$.

For males, bivariate Models 2 identified associations with BMI: Deviations from males' own expected BMI and other males' BMI were associated with CRP. Between-persons BMI interacted with age, but the sign of the interaction coefficient was reverse compared to the corresponding coefficient in females. Specifically, the strength of between-persons BMICRP associations decreased with age. Thus, the CRP gap between low versus high BMI males narrowed with increasing age.

"Ever sexually active" was bivariately associated with CRP, as were nicotine use, alcohol use, low SES, and illness. Notably, when the trajectory of CRP (Model 2) was taken into account, only the BMI variables remained significant. Indeed, the BMI coefficients were the only significant covariates of CRP beyond age and ethnicity in the final model (Model 4). In this model, the coefficient for American Indians decreased by $64 \%$, but remained significant at $b=.04, S E=.01, p=.01$. The reduction of the size of this coefficient was due to the inclusion of the within- and between-persons BMI terms. The age 15 term decreased slightly (by $15 \%$ ) from $b=.07$ to $b=.06, S E=.01, p<.001$.

\section{Testosterone and CRP to Age 16}

Testosterone was assessed to age 16 only and Step 3 repeated all analyses, but to age 16 only and with the inclusion of testosterone. In the final model for females, within- and between-persons testosterone did not reach significance $(b=-0.0007, S E=0.0004, p=.06$, and $b=-0.0004, S E=0.0008, p=.53$, respectively). In final models for males, both within- 
and between-persons testosterone were negatively associated with CRP $(b=-0.0002, S E=$ $0.0001, p=.005$, and $b=-0.0002, S E=0.0001, p=.04$, respectively). Thus, males with higher typical/stable testosterone levels and higher-than-expected increases in testosterone had lower CRP than males with lower typical/stable testosterone levels or lower-thanexpected increases in testosterone. The inclusion of testosterone did not reduce the size of the age coefficient to non-significance. When the entire sample was analyzed together, testosterone by sex (by age) interactions were not significant.

\section{What Explains Sex-Differentiated Accelerated Increases in CRP after Age 15?}

Final analyses for the entire sample (Step 4), using ages 9 to 21, and were conducted in order to understand the factors contributing to sex-differentiated increases in CRP after age 15. Therefore, the age 15 variable was used as an indicator of age. The final model retained all covariates at $p<.10$. Apparent sex differences that had emerged in the separate models for females and males were tested. Results showed that the following terms were significant: age 15 $(b=.10, S E=.02, p<.001)$, American Indian ethnicity $(b=.04, S E=.01, p<.001)$, within-person BMI $(b=.01, S E=.002, p<.001)$, between-persons BMI and its interactions with age and sex $(b=-.01, S E=.003, p<.001$, for the three-way interaction), use of oral contraceptives $(b=.19, S E=.03, p<.001)$, numbers of pregnancies $(b=.11, S E=.02, p<$. $01)$, medication use $(b=.04, S E=.01, p<.01)$, and also the two-way interactions terms between sex and both nicotine use and alcohol use $(b=-.05, S E=.02, p<.05 ; b=.06, S E$ $=.03, p<.05$, respectively). Once all covariates had been taken into account, the size of the coefficient for the age 15 by sex interaction shrank by $67 \%$ to non-significance (from $b=-$. 09 to $b=-.03, S E=.02, p=.10$ ). Taken together, results from Step 4 showed that CRP still increased after age 15-but no longer at different rates for males and females. Follow-up analyses showed that when each variable domain was entered separately, it was the physical/ sexual maturation variables that were most responsible for the reduction of the age $\mathrm{X}$ sex coefficient to non-significance. Testosterone was not included in Step 4, because it was only assayed to age 16 .

\section{Discussion}

Our multilevel prospective-longitudinal study showed that sex disparities in CRP first emerged in late adolescence: mean CRP approximately doubled between ages 16 to 19 in females, increasing to an average value near $2 \mathrm{mg} / \mathrm{L}$ in White, and above $3 \mathrm{mg} / \mathrm{L}$ in American Indian females. Accelerated increases in CRP were not evident in males. This pattern accords with findings from a cross-sectional, nationally-representative study (Ford et al., 2003). CRP > $3 \mathrm{mg} / \mathrm{L}$ has been established as a marker prognostic of disease risk in middle-aged and older adults (Ridker, 2007). Our findings suggest that a substantial proportion of females already meet this cut-off in their late teens/early twenties (26.3\% of females $\geq 19$ years old in our sample, versus $10.3 \%$ of males).

CRP was higher in American Indian compared to White participants at all ages, replicating findings from other indigenous populations (Retnakaran et al., 2006; Wang and Hoy, 2006). The inclusion of covariates of CRP, especially BMI, reduced these ethnic differences substantially, but not fully. Consistent with work on younger (Ford et al., 2004), but not older samples (Kershaw et al., 2010), Black and White participants in the GSMS did not differ in their CRP concentrations, but this finding should be interpreted with caution considering the small number of Black participants. Nevertheless, it is possible that BlackWhite differences in CRP emerge only later in life.

CRP was only moderately stable between ages 9 and 21, and a substantial proportion of variance in CRP was due to within-person changes/fluctuations. Disaggregating within- 
person changes from stable between-persons differences is a new direction for research on inflammatory markers in the early life course.

\section{Correlates of Sex-Differentiated Changes in CRP}

The sex-differentiated increases in CRP during the second decade of life were, in part, accounted for by increasing BMI-CRP associations in females - a finding consistent with work on adult females (Visser et al., 1999; Williams et al., 2004; Khera et al., 2009). After puberty, women typically have more inflammation-enhancing body fat than men (Wozniak et al., 2009), even at the same BMI. In contrast, lean muscle mass increases in males during adolescence, decreasing males' overall percent body fat and weakening BMI-CRP associations. It is possible, however, that BMI is not an ideal indicator of health-related adiposity in post-pubertal males, and alternative measures (e.g., waist circumference) should be examined in future research.

During physical/sexual maturation, females are also exposed to additional inflammatory challenges that are not matched in males. For example, some females begin using oral contraceptives containing sex hormones-such use was robustly linked with higher CRP here. Furthermore, lifetime cumulative exposure to endogenous sex hormones increases, with potentially proinflammatory effects, as suggested by positive associations between the number of pregnancies and CRP levels, even after BMI was taken into account. In turn, testosterone in females did not have a protective anti-inflammatory effect after other covariates had been taken into account. A better understanding is still needed of whether and how endogenous sex hormones contribute to inflammatory processes in young females. In males, physical/sexual maturation appeared to be associated with at least some antiinflammatory processes, as indicated, for example, by the robust negative associations of both, stable between-persons differences in testosterone as well as within-person changes in testosterone with CRP. Together, sex-differentiated changes in associations of CRP with BMI and sex-differentiated physical/sexual maturation experiences were important contributors to the sex-differentiated rate of increases in CRP after age 15.

Some substances are robust correlates of CRP in adults (O'Connor et al., 2009), and indeed, nicotine use was positively associated with CRP in females; the association was reverse for alcohol use. In males, substance use was not a robust covariate of CRP. To date, there are no consistent reports of such sex-differentiated associations of substance use with CRP.

Perhaps critical levels of inflammation or substance use needed to produce consistent CRPsubstance use associations had not yet been reached in males - or differ by sex (Ford et al., 2003).

\section{Limitations and Future Research}

Our report represents the first longitudinal study of sex differences in CRP from childhood to young adulthood, but had several limitations. First, variables not easily assessed in field research, including total amounts and distribution of body fat, physical fitness, dietary intake, and markers of metabolic syndrome were not assessed. These factors could contribute to developing sex differences in CRP. Second, our sample was representative of the counties from which it was recruited, but future research should also test the development of sex differences in CRP in Hispanic and Asian, and larger African American subgroups. Third, assessments took place annually to age 16, and less frequently thereafter. Indeed, we did not have intermediate assessments during the "critical period" of CRP accelerations between ages 16 and 19. However, the NHANES data with their yearly assessments during these ages suggested similar developmental patterns (Ford et al., 2003). 
Finally, although elevated CRP is a robust indicator of cardiovascular disease (CDV) risk in middle-aged and older women, and indeed some of the earlier work establishing CRP > 3 $\mathrm{mg} / \mathrm{L}$ as a risk cut-off was conducted with women (Ridker et al., 1998), the current study cannot determine whether the steep increases in females' CRP during late adolescence contribute to the initiation and/or progression of CVD processes or are part of "normative," healthy development. Further investigation of elevated CRP in young women also is needed, because high CRP is being tested as a promising risk indicator for adverse pregnancy outcomes (Han et al., 2011). Indeed, in our study, CRP was the highest among young women who are at risk for poor health and also poor pregnancy outcomes-including obese (Cnattingius et al., 1998) and American Indian women (Baldwin et al., 2009).

\section{Conclusion}

Sex differences in CRP widen after age 15, in part, because the physical and behavioral changes of adolescence constitute an inflammatory challenge for females while some antiinflammatory influences are instituted for males during this time. Our findings of sexdifferentiated trajectories of CRP add another piece to the puzzle of how to most efficiently use CRP as a marker of disease risk in females and males.

\section{Supplementary Material}

Refer to Web version on PubMed Central for supplementary material.

\section{Acknowledgments}

This research was supported by the National Institute of Mental Health (MH63970, MH63671, MH48085, MH094605), the National Institute on Drug Abuse (DA/MH11301), the William T. Grant Foundation, and a NARSAD Early Career Award to W.E.C.

\section{References}

Angold A, Costello EJ. The Child and Adolescent Psychiatric Assessment (CAPA). J Am Acad Child Adolesc Psychiatry. 2000; 39:39-48. [PubMed: 10638066]

Angold A, Costello EJ, Worthman CM. Pubertal changes in hormone levels and depression in girls. Psychol Med. 1999a; 29:1043-1053. [PubMed: 10576297]

Angold, A.; Cox, A.; Prendergast, M.; Rutter, M.; Simonoff, E.; Costello, EJ.; Ascher, BH. The Young Adult Psychiatric Assessment (YAPA). Duke University Medical Center; Durham, NC: 1999b.

Ascher BH, Farmer EMZ, Burns BJ, Angold A. The Child and Adolescent Services Assessment (CASA): Description and psychometrics. J Emot Behav Disord. 1996; 4:12-20.

Baldwin LM, Grossman DC, Murowchick E, Larson EH, Hollow WB, Sugarman JR, Freeman WL, Hart LG. Trends in perinatal and infant health disparities between rural American Indians and Alaska natives and rural Whites. Am J Public Health. 2009; 99:638-646. [PubMed: 18703453]

Cnattingius S, Bergström R, Lipworth L, Kramer MS. Prepregnancy weight and the risk of adverse pregnancy outcomes. N Engl J Med. 1998; 338:147-152. [PubMed: 9428815]

Cook DG, Mendall MA, Whincup P, Isasi CR. C-reactive protein concentration in children: Relationship to adiposity and other cardiovascular risk factors. Atherosclerosis. 2000; 149:139-150. [PubMed: 10704625]

Copeland WE, Shanahan L, Costello EJ, Angold A. Cumulative prevalence of psychiatric disorders by young adulthood: A prospective cohort analysis from the Great Smoky Mountains Study. J Am Acad Child Adolesc Psychiatry. 2011; 50:252-261. [PubMed: 21334565]

Copeland WE, Shanahan L, Miller S, Costello EJ, Angold A, Maughan B. Outcomes of early pubertal timing in young women: A prospective population-based study. Am J Psychiatry. 2010; 167:12181225. [PubMed: 20478880] 
Copeland WE, Shanahan L, Worthman C, Angold A, Costello EJ. Cumulative depressive episodes predict later C-reactive protein levels: A prospective analysis. Biol Psychiatry. 2012; 71:15-21. [PubMed: 22047718]

Costello EJ, Angold A, Burns BJ, Stangl DK, Tweed DL, Erkanli A, Worthman CM. The Great Smoky Mountains Study of Youth: Goals, designs, methods, and the prevalence of DSM-III-R disorders. Arch Gen Psychiatry. 1996; 53:1129-1136. [PubMed: 8956679]

Costello EJ, Mustillo S, Erkanli A, Keeler G, Angold A. Prevalence and development of psychiatric disorders in childhood and adolescence. Arch Gen Psychiatry. 2003; 60:837-844. [PubMed: 12912767]

Costello EJ, Sung M, Worthman C, Angold A. Pubertal maturation and the development of alcohol use and abuse. Drug Alcohol Depend. 2007; 88:S50-59. [PubMed: 17275214]

Dielubanza EJ, Schaeffer AJ. Urinary tract infections in women. Med Clin North Am. 2011; 95:27-41. [PubMed: 21095409]

Dowd JB, Zajacova A, Aiello AE. Predictors of inflammation in U.S. children aged 3-16 years. Am J Prev Med. 2010; 39:314-320. [PubMed: 20837281]

Eskes T, Haanen C. Why do women live longer than men? Eur J Obstet Gynecol Reprod Biol. 2007; 133:126-133. [PubMed: 17324494]

Ford ES. Body mass index, diabetes, and C-reactive protein among U. S. adults. Diabetes Care. 1999; 22:1971-1977. [PubMed: 10587828]

Ford ES, Giles WH, Mokdad AH, Myers GL. Distribution and correlates of C-reactive protein concentrations among adult US women. Clin Chem. 2004; 50:574-581. [PubMed: 14709450]

Ford ES, Giles WH, Myers GL, Rifai N, Ridker PM, Mannino DM. C-reactive protein concentration distribution among US children and young adults: Findings from the National Health and Nutrition Examination Survey, 1999-2000. Clin Chem. 2003; 49:1353-1357. [PubMed: 12881452]

Gallagher D, Visser M, Sepúlveda D, Pierson RN, Harris T, Heymsfield SB. How useful is body mass index for comparison of body fatness across age, sex, and ethnic groups? Am J Epidemiol. 1996; 143:228-239. [PubMed: 8561156]

Granger DA, Shirtcliff EA, Booth A, Kivlighan KT, Schwartz EB. The "trouble" with salivary testosterone. Psychoneuroendocrinology. 2004; 29:1229-1240. [PubMed: 15288702]

Han YS, Ha EH, Park HS, Kim YJ, Lee SS. Relationships between pregnancy outcomes, biochemical markers and pre-pregnancy body mass index. Int J Obes. 2011; 35:570-577.

Hooton TM, Scholes D, Stapleton AE, Roberts PL, Winter C, Gupta K, Samadpour M, Stamm WE. A prospective study of asymptomatic bacteriuria in sexually active young women. N Engl J Med. 2000; 343:992-997. [PubMed: 11018165]

Kershaw KN, Mezuk B, Abdou CM, Rafferty JA, Jackson JS. Socioeconomic position, health behaviors, and C-reactive protein: a moderated-mediation analysis. Health Psychol. 2010; 29:307316. [PubMed: 20496985]

Khera A, McGuire DK, Murphy SA, Stanek HG, Das SR, Vongpatanasin W, Wians FHJ, Grundy SM, de Lemos JA. Race and gender differences in C-reactive protein levels. J Am Coll Cardiol. 2005; 46:464-469. [PubMed: 16053959]

Khera A, Vega GL, Das SR, Ayers C, McGuire DK, Grundy SM, de Lemos JA. Sex differences in the relationship between C-reactive protein and body fat. J Clin Endocrinol Metab. 2009; 94:32513258. [PubMed: 19567538]

Laaksonen DE, Niskanen L, Punnonen K, Nyyssönen K, Tuomainen TP, Salonen R, Rauramaa R, Salonen JT. Sex hormones, inflammation and the metabolic syndrome: a population-based study. Eur J Endocrinol. 2003; 149:601-608. [PubMed: 14641004]

Lakoski SG, Cushman M, Criqui M, Rundek T, Blumenthal RS, D’Agostino RBJ, Herrington DM. Gender and C-reactive protein: data from the Multiethnic Study of Atherosclerosis (MESA) cohort. Am Heart J. 2006; 152:593-598. [PubMed: 16923436]

McDade T, Burhop J, Dohnal J. High-sensitivity enzyme immunoassay for C-reactive protein in dried blood spots. Clin Chem. 2004; 50:652-654. [PubMed: 14981035]

McDade TW, Leonard WR, Burhop J, Reyes-García V, Vadez V, Huanca T, Godoy RA. Predictors of C-reactive protein in Tsimane' 2 to 15 year-olds in lowland Bolivia. Am J Phys Anthropol. 2005; 128:906-913. [PubMed: 16118783] 
McDade W, Stallings JF, Worthman CM. Psychosocial stress and cell-mediated immune function: Validation of a blood spot method for Epstein-Barr virus antibodies. Am J Phys Anthropol (Suppl). 1997; 24:164-165.

National Center for Health Statistics. Child Health Supplement. In: Adams, P.; Hardy, A., editors. Current Estimates from the National Health Interview Survey. Hyattsville, MD: 1988.

O'Connor MF, Bower JE, Cho HJ, Creswell JD, Dimitrov S, Hamby ME, Hoyt MA, Martin JL, Robles TF, Sloan EK, Thomas KS, Irwin MR. To assess, to control, to exclude: Effects of biobehavioral factors on circulating inflammatory markers. Brain Behav Immun. 2009; 23:887897. [PubMed: 19389469]

Retnakaran R, Hanley AJ, Connelly PW, Harris SB, Zinman B. Elevated C-reactive protein in Native Canadian children: an ominous early complication of childhood obesity. Diabetes Obes Metab. 2006; 8:483-491. [PubMed: 16918582]

Ridker P, Buring J, Shih J, Matais M, Hennekens C. Prospective study of C-reactive protein and the risk of future cardiovascular events among apparently healthy women. Circulation. 1998; 98:731733. [PubMed: 9727541]

Ridker PM. C-reactive protein and the prediction of cardiovascular events among those at intermediate risk: Moving an inflammatory hypothesis toward consensus. J Am Coll Cardiol. 2007; 29:2129_ 2138. [PubMed: 17531663]

Rifai N, Ridker PM. Population distributions of C-reactive protein in apparently healthy men and women in the United States: Implication for clinical interpretation. Clin Chem. 2003; 49:666-669. [PubMed: 12651826]

Shah T, Casas JP, Cooper JA, Tzoulaki I, Sofat R, McCormack V, Smeeth L, Deanfield JE, Lowe GD, Rumley A, Fowkes FGR, Humphries SE, Hingorani AD. Critical appraisal of CRP measurement for the prediction of coronary heart disease events: New data and systematic review of 31 prospective cohorts. Int J Epidemiol. 2009; 38:217-231. [PubMed: 18930961]

Skinner AC, Steiner MJ, Henderson FW, Perrin EM. Multiple markers of inflammation and weight status: Cross-sectional analyses throughout childhood. Pediatrics. 2010; 125:801-819.

Visser M, Bouter LM, McQuillan GM, Wener MH, Harris TB. Elevated C-reactive protein levels in overweight and obese adults. JAMA. 1999; 282:2131-2135. [PubMed: 10591334]

Wang Z, Hoy WE. Population distribution of high sensitivity C-reactive protein values in Aboriginal Australians: a comparison with other populations. Clin Biochem. 2006; 39:277-281. [PubMed: 16405882]

Williams MJ, Williams SM, Milne BJ, Hancox RJ, Poulton R. Association between C-reactive protein, metabolic cardiovascular risk factors, obesity and oral contraceptive use in young adults. Int J Obes Relat Metab Disord. 2004; 28:998-1003. [PubMed: 15211365]

Worthman CM, Stallings JF. Hormone measures in finger-prick blood spot samples: New field methods for reproductive endocrinology. Am J Phys Anthropol. 1997; 103:1-21. [PubMed: 9185948]

Wozniak SE, Gee LL, Wachtel MS, Frezza EE. Adipose tissue: The new endocrine organ? A review article. Dig Dis Sci. 2009; 54:1847-1856. [PubMed: 19052866] 
Observed Means

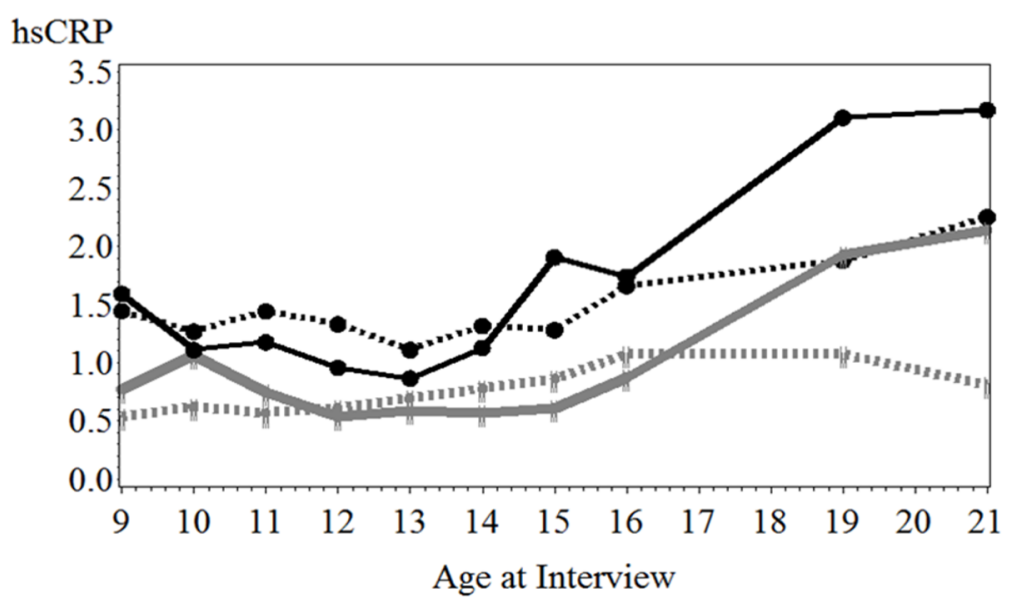

Solid lines $=$ females. Dashed Lines $=$ males.

Black Lines $=$ American Indian. Grey Lines $=$ White

Figure 1.

Means of hs-CRP for American Indian and White females and males from ages 9 to 21 . 
Table 1

Descriptive statistics of CRP and its covariates for females and males.

\begin{tabular}{|l|c|c|c|c|}
\hline & \multicolumn{2}{|c|}{$\begin{array}{c}\text { Females } \\
\text { N=2,704 }\end{array}$} & \multicolumn{2}{c|}{$\begin{array}{c}\text { Males } \\
\text { N3191 }\end{array}$} \\
\hline & N/M & \%/SD & N/M & \%/SD \\
\hline CRP & & & & \\
\hline Raw hs-CRP variable & 0.97 & 1.71 & 0.80 & 1.35 \\
\hline BMI & & & & \\
\hline Raw BMI Score & 22.60 & 6.08 & 22.09 & 5.14 \\
\hline Physical/Sexual Maturation & & & & \\
\hline Menarche before 11 (0,1) & 327 & 13.03 & -- & -- \\
\hline Oral Contraceptive (0,1) & 147 & 6.51 & -- & -- \\
\hline Pregnancies (0,1,2+) & 0.06 & 0.26 & -- & -- \\
\hline Ever sexually active (0,1) & 644 & 19.38 & 620 & 14.88 \\
\hline Multiple sex. partners $(0,1)$ & 89 & 2.75 & 132 & 3.24 \\
\hline Substance Use & & & & \\
\hline Nicotine Use (0,1) & 440 & 12.25 & 673 & 14.27 \\
\hline Alcohol Use (0,1) & 375 & 13.78 & 450 & 11.47 \\
\hline Illicit Drug Use (0,1) & 202 & 6.93 & 354 & 8.94 \\
\hline Controls & & & & \\
\hline Low SES & 835 & 23.15 & 896 & 19.36 \\
\hline Sick in past 12 months (0,1) & 960 & 37.13 & 1005 & 31.81 \\
\hline Medication Use (0,1) & 903 & 31.35 & 888 & 28.72 \\
\hline
\end{tabular}

$\mathrm{N}=$ number of observations

$\mathrm{M}=$ mean

$\%=$ weighted percentage

$\mathrm{SD}=$ standard deviation 


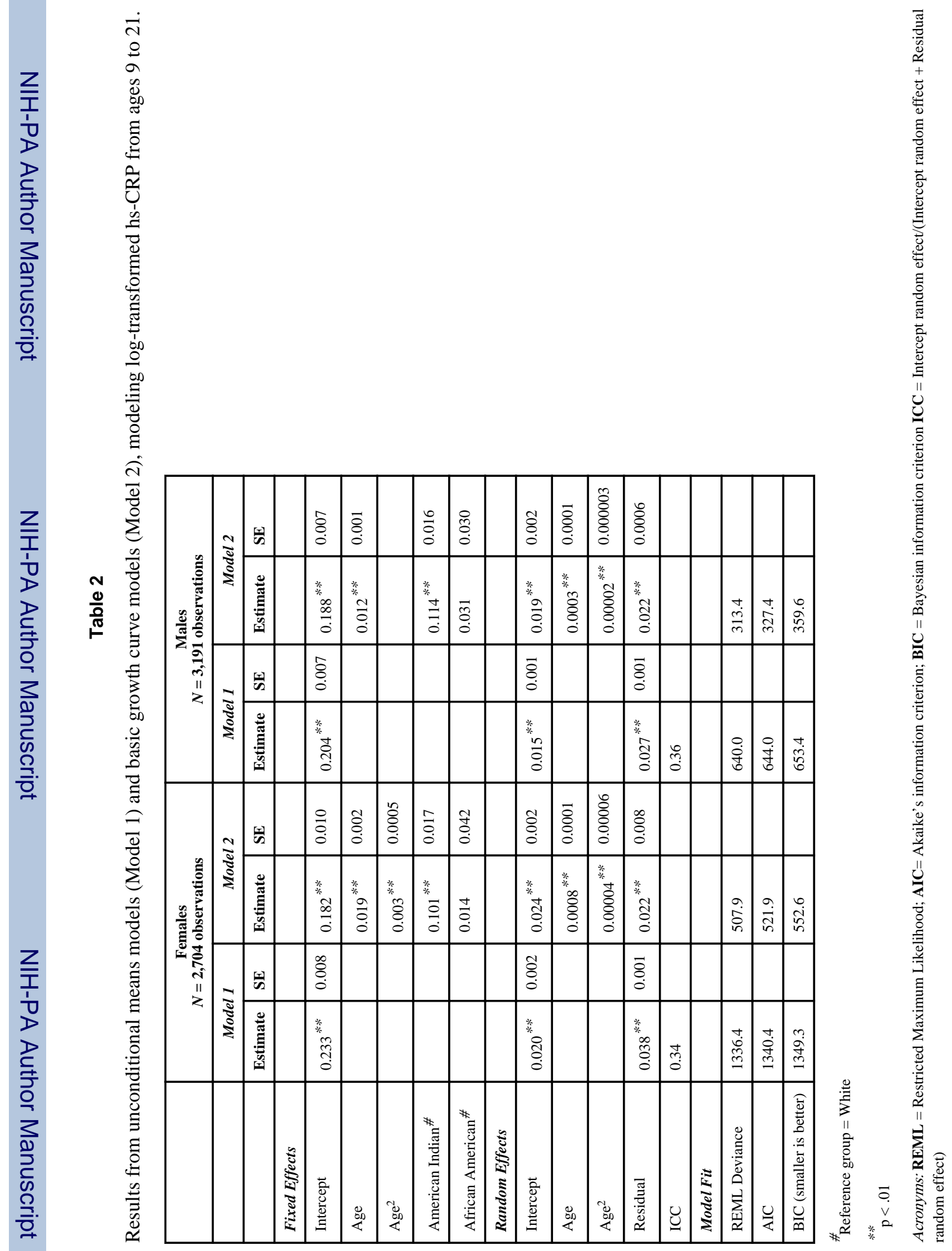




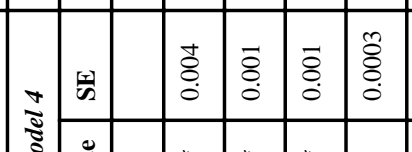

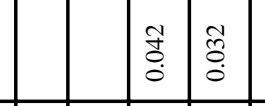




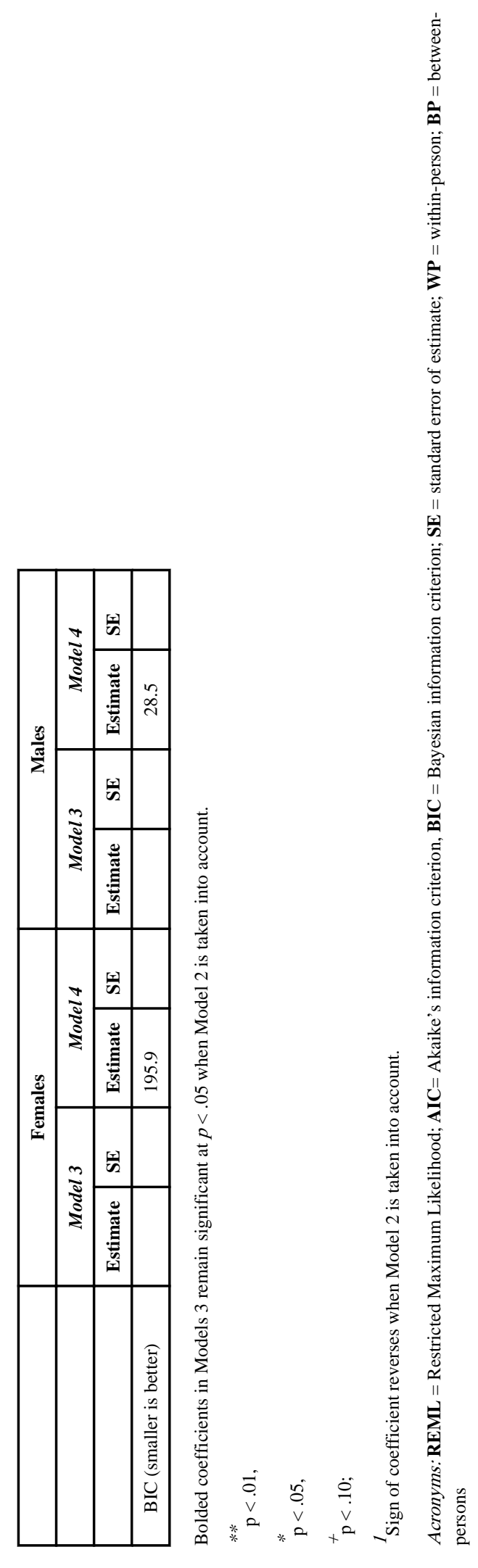

Psychoneuroendocrinology. Author manuscript; available in PMC 2014 October 01. 